\title{
Health seeking behavior and experiences related to HIV treatment of people living with HIV (PLHIV) in Yangon, Myanmar
}

Hsu Nwe Yee Aung1, Arthorn Riewpaiboon ${ }^{2}$, Montaya Sunantiwat ${ }^{2}$, San Hone ${ }^{3}$, Montarat Thavorncharoensap $2,4^{*}$

1 Master of Science Program in Social, Economic, and Administrative Pharmacy, Department of Pharmacy, Faculty of Pharmacy, Mahidol University, Bangkok, Thailand

2 Social and Administrative Pharmacy Excellence Research (SAPER) unit, Department of Pharmacy, Faculty of Pharmacy, Mahidol University, Bangkok, Thailand

3 Department of Public Health, Ministry of Health and Sports, Nay Pyi Taw, Myanmar

4 Social, Economic and Administrative Pharmacy Division, Department of pharmacy, Faculty of pharmacy, Mahidol University, Bangkok, Thailand

*Corresponding author:

Montarat Thavorncharoensap montarat.tha@mahidol.ac.th

\section{Keywords:}

Health seeking behavior, HIV, Treatment, Experience, Myanmar, PLHIV

\begin{abstract}
This study aims to examine health seeking behavior and HIV treatment experiences among people living with HIV (PLHIV) in Yangon, Myanmar. To investigate health seeking behavior, faceto-face structure interview was conducted among 246 participants, recruited from the selected 4 self-health groups (SHG) in Yangon. In-depth interview was conducted among 10 PLHIV to explore experiences regarding HIV treatment. Majority of our participants $(62 \%)$ in the structured interview were key populations with the mean duration of HIV diagnosis of 8.5 years. We found that International nongovernmental organization (INGO)/nongovernmental organization (NGO) clinics were the main sources for diagnosis (73.2\%). Similarly, INGO/NGO clinics were mentioned as the first treatment facility by most participants $(85.0 \%)$, followed by public facilities (10.2\%). Status of key population, education, place of diagnosis, duration of HIV infected, and person who motivated for seeking treatment influenced preferences for first treatment facility. Main reasons for seeking care at the treatment facility were confidentiality, suggested from others, and comfort and warm service. About $65 \%$ and $35 \%$ mentioned that their current treatment facilities were INGO/NGO clinic, and public facilities, respectively. Place of first treatment facility was the important factor predicting preference for current treatment facility. Stigma and discrimination as well as feeling inconveniences during treatment services were identified. Positive experiences at INGO/NGO was mentioned.
\end{abstract}

\section{INTRODUCTION}

Health seeking behavior (HSB) was defined as any activities chosen and undertaken by individuals who perceived their health problems and tried to find the appropriate remedy ${ }^{1}$. Health seeking behavior of people living with HIV (PLHIV) includes self-treatment, visit to the hospital, and use of alternative health care services such as traditional healer and spiritual ${ }^{2-7}$. For PLHIV, appropriate health seeking behavior could lead to timely and effective HIV treatment, resulting in the reduction of complications and mortality ${ }^{8-10}$.

Myanmar is the country with the second highest number of PLHIV in Southeast Asia region with 220,000 PLHIV ${ }^{11}$, representing around $0.57 \%$ of adult age $\geq 15$ years in $2017^{11}$. Yangon, second capital of Myanmar, was identified as a key city to end AIDS epidemic within Asia- Pacific region ${ }^{12}$. As of 2015 , approximately $50 \%$ of the overall
Pharmaceutical Sciences Asia (C) 2021 by Faculty of Pharmacy, Mahidol University, Thailand is licensed under CCBY-NC-ND 4.0. To view a copy of this license, visit https:// www.creativecommons.org/ licenses/by-nc-nd/4.0/ 
funding of the HIV response in Myanmar came from Global fund ${ }^{13}$. Nevertheless, the proportion of government spending on HIV increased threefold since 2012 , representing $12 \%$ of the overall funding for HIV in $2015^{13}$

In Myanmar, antiretroviral therapy (ART) has been provided free of charge at public and private NGO facilities ${ }^{14}$. Regarding ART provision, after HIV status was confirmed patients were enrolled and assessed for eligibility for ART initiation. If patients were eligible ART were started otherwise Pre-ART care would be provided ${ }^{15}$. Coverage of ART substantially increases from $25 \%$ in 2012 to $49 \%$ in 2015 and $66 \%$ in $2017^{11}$. The number of ART facilities also increased from 147 in 2013 to 240 in $2015^{13}$. The percentage of HIV patients who received ART from public sectors increased from $32 \%$ in 2011 to $56 \%$ in $2015^{13}$. Nevertheless, recent study found that many PLHIVs in Myanmar presented to hospitals in their late state of disease ${ }^{16}$. Economic burden of HIV borne by each PLHIV in Yangon was estimated at $\$ 230$ (2017 value $)^{17}$.

Understand health seeking behavior and treatment experiences is vitally important in appropriately response to the actual demand of PLHIV, leading to the improvement and satisfaction of HIV treatment programs. To date, no such study has ever been conducted in Myanmar before. Thus, our study aims to examine health seeking behavior, determinants of health care seeking behavior, and experiences regarding HIV treatment among PLHIV in Yangon.

\section{MATERIALS AND METHODS}

Cross-sectional survey using face-to-face interview was conducted to examine HIV health seeking behaviour while in-depth interview was used to explore treatment experiences of PLHIV.

\subsection{Sample and settings}

As this study was part of a main study aimed to examine economic burden of PLHIV the total number of 246 patients was required for this study ${ }^{17}$. It should be noted that this sample size is adequate to estimate the proportion of PLHIV receiving care at the public facility at $50 \%$ with the margin of error at least $7 \%$. The participants were selected based on convenient sampling technic from the selected self-help groups (SHGs), using proportional to size method.

Self-help groups (SHGs) are the PLHIV peer support groups, which are supported by many organizations including NAP, INGO/NGOs, and community based. The purposes of SHGs are to share experiences, encourage disclosure, reduce stigma and discrimination, improve self-esteem, enhance patient's coping skill as well as ART adherence. Based on data from Myanmar Positive Group (MPG), a National PLHIV Network in Myanmar, there are 27 SHGs within Yangon metropolitan area. The following 4 SHGs with the members at least 50 patients were purposively selected; 1) Nway Htay Eain, 2) Positive Muslim Group, 3) Golden Future, and 4) Arr Mann Thit.

Inclusion criteria included: 1) being HIV positive adults with the age $\geq 18$ years, 2) were on ART treatment $\geq 1$ year, 3) has been living in Yangon Metropolitan Area $\geq 1$ year, and 4) can understand Myanmar language.

For in-depth interview, participants who have rich experiences and willing to talk and express their experiences regarding HIV care service were purposively selected with the suggestion from patient group leaders in each SHG. Selection continued until no more additional points and information were raised.

\subsection{Data collection}

Face-to-face interview using structured questionnaire were conducted between March and April, 2018. The development of questionnaire was guided by literature review and the Andersen's behavioral model for health service utilization ${ }^{18}$. Content validity and face validity was conducted among 3 experts (2- methodologist expert, and 1local content expert) during the questionnaire development process. For each question, itemobjective congruence (IOC) was calculated. Pilot testing was conducted to evaluate the feasibility and understanding of the questionnaire. The final questionnaire consists of 2 main parts; 1) general and clinical characteristics, and 2) health seeking behavior (i.e. place of diagnosis and treatment, first facility for HIV treatment, persons who motivated to seek care at the first treatment facility, reasons for choosing treatment facility, and current HIV treatment facility).

For in-depth interview, a series of openended questions were asked. Examples of questions were; "Could you describe the HIV service you received?", and How do you feel about your HIV service treatment?".

Informed consents were obtained before all interview. Ethical approval for the study was 
granted by Ethical Review Committee, Department of Medical Research, Ministry of Health and Sports, the Republic of Myanmar.

\subsection{Data analysis}

Characteristics of participants and health seeking behaviour were summarized using descriptive statistics. To determine determinants of health seeking behaviour, characteristics of the people receiving treatment at different facilities were compared using Chi-square test, T-test, or ANOVA. Non-parametric statistics were adopted when data was not normally distributed. Thematic analysis was employed for in-depth interview.

\section{RESULTS}

Socio-demographic and clinical characteristics of study participants were described in Table 1 . Of the total 246 participants, $60.2 \%$ were female. Majority of the participants $(63 \%)$ had monthly family income less than 300,000 MMK (1US\$ = 1,338.0 MMK). Approximately $70 \%$ of our samples were key population (i.e. men who have sex with men (MSM), sex worker (SW), and injected drug user (IDU)) with the mean duration of HIV infection of 8.57 years.

Table 1. Characteristics of participants.

\begin{tabular}{|c|c|c|}
\hline \multirow{2}{*}{$\begin{array}{l}\text { Characteristics } \\
\text { Gender }\end{array}$} & \multicolumn{2}{|c|}{ n $(\%)$ or Mean \pm SD } \\
\hline & & \\
\hline Male & 98 & $(39.8 \%)$ \\
\hline Female & 148 & $(60.2 \%)$ \\
\hline Age & \multicolumn{2}{|c|}{$36 \pm 7.2$} \\
\hline \multicolumn{3}{|l|}{ Education } \\
\hline Primary school or less $(\leq$ Grade 5 ) & 82 & $(33.3 \%)$ \\
\hline Middle school - High school (Grade 6-11) & 145 & $(59.0 \%)$ \\
\hline Bachelor degree or above & 19 & $(7.7 \%)$ \\
\hline \multicolumn{3}{|l|}{ Marital status } \\
\hline Single & 70 & $(28.5 \%)$ \\
\hline Married/living together & 96 & $(39.0 \%)$ \\
\hline Divorce/separated/widowhood & 80 & $(32.5 \%)$ \\
\hline Monthly family income (MMK) & \multicolumn{2}{|c|}{$326,823 \pm 256,269$} \\
\hline \multicolumn{3}{|l|}{ Type of key population } \\
\hline Not key population & 93 & $(37.8 \%)$ \\
\hline Men who have sex with men (MSM) & 46 & $(18.7 \%)$ \\
\hline Sex worker $(\mathrm{SW})$ & 93 & $(37.8 \%)$ \\
\hline Injected drug user (IDU) & 14 & $(5.7 \%)$ \\
\hline Duration of HIV infected (years) & 8.57 & $(4.3 \%)$ \\
\hline \multicolumn{3}{|l|}{ Self Help Group } \\
\hline Nway Htway Eain & 74 & $(30.0 \%)$ \\
\hline Positive Muslim Group & 74 & $(30.0 \%)$ \\
\hline Arr Mann Thit & 62 & $(25.0 \%)$ \\
\hline Golden Future & 36 & $(15.0 \%)$ \\
\hline \multicolumn{3}{|l|}{ Key population and duration of HIV infected } \\
\hline Non-key population with HIV infected $\leq 5$ years & 15 & $(6.1 \%)$ \\
\hline Non-key population with HIV infected $6-10$ years & 32 & $(13.0 \%)$ \\
\hline Non-key population with HIV infected $>10$ years & 46 & $(18.7 \%)$ \\
\hline Key population with HIV infected $\leq 5$ years & 62 & $(25.2 \%)$ \\
\hline Key population with HIV infected $\overline{6}-10$ years & 52 & $(21.1 \%)$ \\
\hline Key population with HIV infected $>10$ years & 39 & $(15.8 \%)$ \\
\hline Duration on ART (years) & 6.8 & $(3.9)$ \\
\hline
\end{tabular}

*1US\$ = 1,338.0 MMK

\subsection{Health seeking behaviour}

Health seeking behavior of participants was presented in Table 2. Majority of our participants (73\%) took HIV diagnosis at INGO /NGO clinics. Similarly, INGO/NGO clinics were mentioned by $85 \%$ of the participants as the first facility for HIV treatment. It should be noted that approximately $67 \%-72 \%$ of the participants who got diagnosis and first treatment at $\mathbb{N G O / N G O}$ were key population. Only 12 participants $(4.6 \%)$ reported seeking their first HIV treatment at private facility/ drugstore/traditional medicine. Majority of the 12 participants were non-key population and were diagnosed for $>10$ years. For current 
treatment facilities, about $65 \%$ and $35 \%$ of participants were currently seeking HIV care at INGO/NGO clinics, and public facilities, respectively. Suggestion from others, confidentiality, and comfort and warm services were the main reasons for choosing the HIV treatment facility.

Table 3 presents determinants of first treatment facility preference. Age, key population status, education, place at diagnosis, person who motivated to get treatment, and duration of HIV infected were associated with preference for first treatment facility. It was found that $43.5 \%$, $20 \%$, and $41.7 \%$ of PLHIV who received their first treatment at INGO/NGO clinics, government facilities, and self-treatment/private facilities mentioned their friends as people who motivated them to get treatment. We found that about $67 \%$,
$36 \%$, and $33.3 \%$ of PLHIV who received their first treatment at INGO/NGO clinics, government facilities, and self-treatment private facilities were key population. Approximately, 84\%, $16 \%$, and $8.3 \%$ of PLHIV who received their first treatment at INGO/NGO clinics, government facilities, and self-treatment/private facilities got diagnosed at INGO/NGO clinics. About 31.1\%, $44 \%$, and $75 \%$ of patients, who received their first treatment at INGO/NGO, government facilities, and self-treatment/private facilities were infected for more than 10 years.

Table 4 displays determinants of current treatment facility preference. It was found that place of first treatment facility was the determinant of current treatment facility. Approximately $93 \%$ of PLHIV who were currently receiving treatment at $\mathrm{INGO} / \mathrm{NGO}$

Table 2. Health seeking behavior of the participants.

\begin{tabular}{|c|c|c|}
\hline Health seeking behavior & $\mathbf{n}$ & $\%$ \\
\hline \multicolumn{3}{|l|}{ Place of diagnosis } \\
\hline Public facility (laboratory/hospital/ health center) & 37 & 15.0 \\
\hline Private facility (laboratory/hospital/ clinic) & 29 & 11.8 \\
\hline INGO/NGO clinic & 180 & 73.2 \\
\hline \multicolumn{3}{|l|}{ First facility for HIV treatment } \\
\hline Self-treatment (drugstore \& traditional medicine) & 4 & 1.6 \\
\hline Private facility (laboratory/hospital/clinic) & 8 & 3.3 \\
\hline INGO/NGO clinic & 209 & 85.0 \\
\hline Public facility (laboratory/hospital/ health center) & 25 & 10.2 \\
\hline \multicolumn{3}{|l|}{ Reasons for seeking care at the 1 st treatment facility } \\
\hline Cheap/ free of charge & 36 & 14.6 \\
\hline Accessibility & 74 & 30.1 \\
\hline Confidential & 137 & 55.7 \\
\hline Comfort and warm service & 96 & 39.0 \\
\hline Quality of service & 36 & 14.6 \\
\hline Suggestion from others & 166 & 67.5 \\
\hline Others & 18 & 7.3 \\
\hline \multicolumn{3}{|l|}{ Person who motivated to seek care at the 1 st treatment facility } \\
\hline Patient's him/herself & 42 & 17.1 \\
\hline Spouse/ lover & 22 & 8.9 \\
\hline Parents & 17 & 6.9 \\
\hline Relatives & 6 & 2.4 \\
\hline Friends/neighbor/colleague & 79 & 32.1 \\
\hline Health care professional & 68 & 27.6 \\
\hline Others & 12 & 4.9 \\
\hline \multicolumn{3}{|l|}{ Current HIV treatment facility } \\
\hline NGO clinic/INGO clinic & 160 & 65.0 \\
\hline Public facility (hospital/ health center) & 86 & 35.0 \\
\hline \multicolumn{3}{|l|}{ Other HIV treatment facilities } \\
\hline No & 228 & 92.7 \\
\hline Yes & 18 & 7.3 \\
\hline \multicolumn{3}{|l|}{ Reason for seeking other treatment facilities } \\
\hline Free of charge & 2 & 11.1 \\
\hline Easily access & 6 & 33.3 \\
\hline Confidential & 2 & 11.1 \\
\hline Good quality service & 2 & 11.1 \\
\hline Being referred from previous health center & 14 & 77.8 \\
\hline Suggestion from others (friend/colleague/neighbor/relative/health staff) & 3 & 16.7 \\
\hline
\end{tabular}


as compared to $70 \%$ of the PLHIV, who were currently receiving treatment at government facilities mentioned that their first treatment facility was INGO/NGO clinics.

\subsection{Experiences related to HIV treatment}

Characteristics of the 10 participants enrolled in the in-depth interview were presented in Table 5. Significant themes emerged as follows; 1) experiencing stigma and discrimination, 2) appreciating holistic care and support from INGO/NGO clinics, and 3) feeling inconvenience due to limited services, treatment facilities, and waiting time crimination.

Theme 1. Experiencing stigma and dis-

Perceived stigma and discrimination were vividly presented. Sense of keeping HIV patients' confidentiality was neglected by health care providers.

"While I was in hospital for abdominal surgery, staffs in hospital pointed me with finger and call me 'retro', 'retro' (retro-positive). It was really shameful..... They washed my bed as soon as I was discharged." (Participant no.5, a sex worker who was diagnosed in 2010).

"...One of my peer friends went to hospital to treat side effects. The staff shouted at us without any reason. My friend told me that she didn't want to go to hospital anymore. Since then I was afraid to go hospital........... While we were waiting to take ART in public ART site, a staff come out and asked loudly us, 'How many tablet do you still have?' There are many non-HIV patients nearby. We really don't want someone to

Table 3. Determinants of first treatment facility.

\begin{tabular}{|c|c|c|c|c|c|c|c|}
\hline \multirow{2}{*}{$\begin{array}{l}\text { Characteristics } \\
\text { Gender }\end{array}$} & \multicolumn{7}{|c|}{ First treatment facility } \\
\hline & \multicolumn{2}{|c|}{$\begin{array}{c}\text { Self-treatment and } \\
\text { private facilities } \\
(\mathrm{N}=12)\end{array}$} & \multicolumn{2}{|c|}{$\begin{array}{c}\text { INGO/ } \\
\text { NGO Clinic } \\
(\mathbf{N}=\mathbf{2 0 9}) \\
\end{array}$} & \multicolumn{2}{|c|}{$\begin{array}{l}\text { Government facility } \\
\text { (N=25) }\end{array}$} & P-value \\
\hline Male & 3 & $(25.0 \%)$ & 82 & $(39.2 \%)$ & 13 & $(52.0 \%)$ & \\
\hline Female & 9 & $(75.0 \%)$ & 127 & $(60.8 \%)$ & 12 & $(48.0 \%)$ & \\
\hline Age (Year) & & & & & & & 0.003 \\
\hline $18-29$ & 3 & $(25.0 \%)$ & 48 & $(23.0 \%)$ & 2 & $(8.0 \%)$ & \\
\hline $30-39$ & 3 & $(25.0 \%)$ & 98 & $(46.9 \%)$ & 8 & $(32.0 \%)$ & \\
\hline $40-49$ & 5 & $(41.7 \%)$ & 57 & $(27.3 \%)$ & 10 & $(40.0 \%)$ & \\
\hline$\geq 50$ & 1 & $(8.3 \%)$ & 6 & $(2.9 \%)$ & 5 & $(20.0 \%)$ & \\
\hline Education & & & & & & & $<0.001$ \\
\hline$\leq$ Primary school & 2 & $(16.7 \%)$ & 73 & $(34.9 \%)$ & 7 & $(28.0 \%)$ & \\
\hline Middle-high school & 10 & $(83.3 \%)$ & 124 & $(59.3 \%)$ & 11 & $(44.0 \%)$ & \\
\hline Bachelor degree & 0 & $(0.0 \%)$ & 12 & $(5.7 \%)$ & 7 & $(28.0 \%)$ & \\
\hline Marital status & & & & & & & 0.230 \\
\hline Single & 1 & $(8.3 \%)$ & 60 & $(28.7 \%)$ & 9 & $(36.0 \%)$ & \\
\hline Married & 5 & $(41.7 \%)$ & 85 & $(40.7 \%)$ & 6 & $(24.0 \%)$ & \\
\hline Divorced/separated/widow & 6 & $(50.0 \%)$ & 64 & $(30.6 \%)$ & 10 & $(40.0 \%)$ & \\
\hline Income (MMK)* & & & & & & & 0.877 \\
\hline$<300,000$ & 8 & $(66.7 \%)$ & 131 & $(62.7 \%)$ & 15 & $(66.0 \%)$ & \\
\hline $300,000-500,000$ & 2 & $(16.7 \%)$ & 44 & $(22.1 \%)$ & 4 & $(16.0 \%)$ & \\
\hline$>500,000$ & 2 & $(16.7 \%)$ & 34 & $(16.3 \%)$ & 6 & $(24.0 \%)$ & \\
\hline Key population & & & & & & & 0.001 \\
\hline Yes & 4 & $(33.3 \%)$ & 140 & $(67.0 \%)$ & 9 & $(36.0 \%)$ & \\
\hline No & 8 & $(66.7 \%)$ & 69 & $(33.0 \%)$ & 16 & $(64.0 \%)$ & \\
\hline Person who motivated to get treatment & & & & & & & $<0.001$ \\
\hline Patients and family & 3 & $(25.0 \%)$ & 32 & $(15.3 \%)$ & 13 & $(52.0 \%)$ & \\
\hline Friends & 5 & $(41.7 \%)$ & 91 & $(43.5 \%)$ & 5 & $(20.0 \%)$ & \\
\hline Health care professional & 2 & $(16.7 \%)$ & 78 & $(37.3 \%)$ & 5 & $(20.0 \%)$ & \\
\hline Other & 2 & $(16.7 \%)$ & 8 & $(3.8 \%)$ & 2 & $(8.0 \%)$ & \\
\hline Place of diagnosis & & & & & & & $<0.001$ \\
\hline Government & 4 & $(33.3 \%)$ & 20 & $(9.6 \%)$ & 13 & $(52.0 \%)$ & \\
\hline Private & 7 & $(58.3 \%)$ & 14 & $(6.7 \%)$ & 8 & $(32.0 \%)$ & \\
\hline NGO & 1 & $(8.3 \%)$ & 175 & $(83.7 \%)$ & 4 & $(16.0 \%)$ & \\
\hline Duration of HIV infected & & & & & & & 0.016 \\
\hline$\leq 5$ years & 0 & $(0.0 \%)$ & 69 & $(33.0 \%)$ & 8 & $(32.0 \%)$ & \\
\hline $6-10$ years & 3 & $(25.0 \%)$ & 75 & $(35.9 \%)$ & 6 & $(24.0 \%)$ & \\
\hline$>10$ years & 9 & $(75.0 \%)$ & 65 & (31.1\%) & 11 & $(44.0 \%)$ & \\
\hline
\end{tabular}


Table 4. Determinants of current treatment facility.

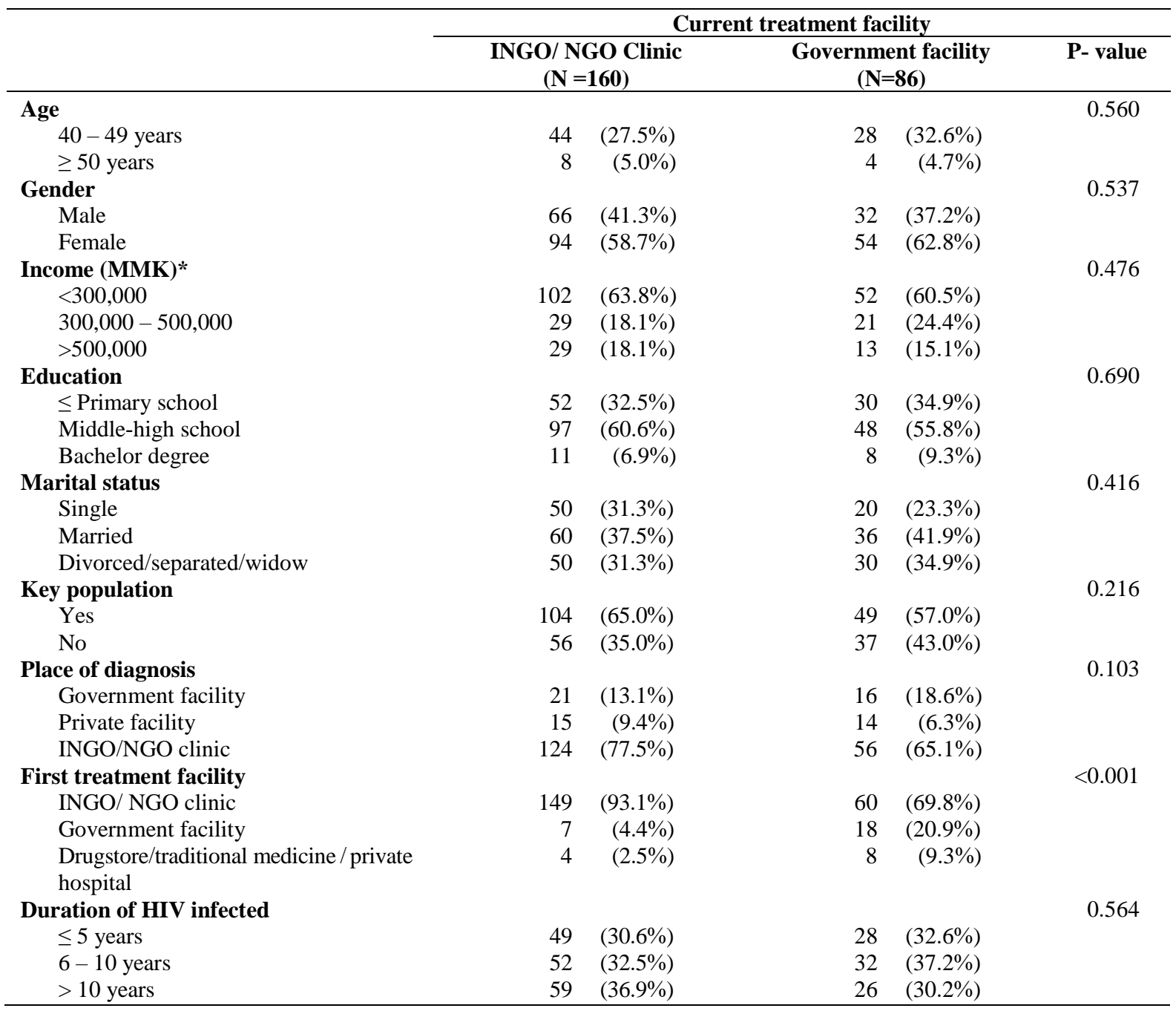

Table 5. Characteristics of qualitative participants.

\begin{tabular}{llllr}
\hline Participant & Gender & Age & Type of key population & $\begin{array}{c}\text { Duration of HIV infected } \\
\text { (Years) }\end{array}$ \\
\hline 1 & Female & 44 & Non- key population & 13 \\
2 & Male & 28 & MSM & 5 \\
3 & Female & 43 & Non- key population & 16 \\
4 & Female & 38 & Ex-SW & 10 \\
5 & Female & 34 & SW & 8 \\
6 & Male & 42 & Non- key population & 18 \\
7 & Female & 27 & Ex-SW & 11 \\
8 & Male & 40 & MSM & 9 \\
9 & Female & 35 & Ex-SW & 13 \\
10 & Male & 24 & MSM & 5
\end{tabular}

$\mathrm{MSM}=$ Men who have sex with men, $\mathrm{SW}=$ sex worker

know about our disease. She has just wanted to finish her work as soon as possible. She did not care about us." (Participant no.5, a sex worker who was diagnosed in 2010).

"The staff took my referral book and threw it on the table.......I thought that the result should be enclosed in an envelope. They gave us an envelope and the results separately. Everyone near me can see the results. There are many nonHIV patients who can read the results. They might know that I am the HIV positive patient." (Participant no.2, a MSM who was diagnosed in 2013).

"When I went to a dental clinic I was 
charged more than double price once I told them that I was HIV positive" (Participant no. 6, nonkey population, who was diagnosed in 2000).

In response to the stigmatization, some patients choose to receive their treatment from the facility that is far from their home.

"We chose ART sites which are far from our place, as we afraid that someone know our condition..." (Participant no.5, a sex worker who was diagnosed in 2010).

Theme 2. Appreciating inclusive care and holistic support from peer counselors in INGO /NGO clinics.

Ambience and caring services offered by INGO/NGO clinics was appreciated by many patients. After entering INGO clinics, participants could perceive relaxing and welcoming atmosphere. All supportive care including food and transportation allowance were prepared and offered. Patients were encouraging to join SHGs to express their sufferings, share their experiences and boost their self-confidence.

"...The NGO clinic gives me transportation allowance whenever I go and check hepatitis $C$ infection... some nutritional supports were provided once every three months. Base on their project, I'm really happy." (Participant no. 4, ex-sex worker who was diagnosed in 2008).

“...I got counseling every week. Every Wednesday, all PLHIV gathered and shared their experiences and gave strength to each other" (Participant no.8, a MSM who was diagnosed in 2009).

"...The health care providers are also very kind to us. I felt warmness from their kind manner. I used to go there from morning to late evening to talk with health care providers and peers..." (Participant no.5, a sex worker who was diagnosed in 2010).

Theme 3. Feeling inconvenience due to limited services, treatment facilities, and waiting time.

Many participants complained about the limited services as in some public sites, where only ART treatment was provided. Thus, patients needed to go to other facilities for their CD4 and viral load checking. Traveling cost and waiting time were also problem for patients.

"Normally, I have to check CD4 in December, but I haven't checked it. In the past, when I was in INGO clinic, the clinic told me a date to come for checking CD4... But, in public site, the staff did not tell anything. Moreover, I was allowed to come to the site only on the schedule date to pick up ART. Next time, I planned to ask the staff when and where I should go for CD4 check. I also need referral letter from regional Nation AIDS Program Office if I need to go for CD4 check at National Health Lab. So, there is one more step to go for me." (Participant no.7, ex-sex worker who was diagnosed in 2007).

"I was transferred to government ART site from INGO clinic...I can only get ART there. Now I am worry if I have to go to other places to test for opportunistic infection and blood test. Do I have to pay for those services? I am not rich. Oh! I can get one-stop services with free of charge in INGO clinic, my previous treatment facility....." (Participant no.5, a sex worker who was diagnosed in 2010).

Some participants expressed their worry about opportunity infections, especially TB. Long waiting time at public ART sites in the limited area meant increasing risk for opportunity infection for HIV patients.

"In government ART site, TB patients also come to pick up their drugs. All HIV and TB patients are waiting together in the same space. $T B$ can be transmitted very easily. We, HIV patients, are easily to get TB infected. I was really afraid of TB." (Participant no.7, ex-sex worker who was diagnosed in 2007).

"...While I was waiting for ART in government ART site, I met many TB patients. $I$ was really afraid of getting $T B$ because it is very easy to be transmitted and get resistant...."' (Participant no.5, a sex worker who was diagnosed in 2010).

\section{DISCUSSION}

We found that $73 \%$ and $85 \%$ of participants received HIV diagnosis and first treatment at INGO/NGO clinics, respectively. About $65 \%$ and $35 \%$ reported that they were currently seeking $\mathrm{HIV}$ care at INGO/NGO clinics and public facilities, respectively. The findings that majority of our participants received HIV diagnosis and first treatment at INGO/NGO health clinics was consistent with the previous statistics ${ }^{13}$, which indicated that INGO/NGO plays a major role in HIV service delivery in Myanmar. In addition, it should be noted that our participants were members of SHG that worked mainly with $\mathrm{NGO/INGO,}$ and most of them were diagnosed for more than 6 years when ART were mainly offered by NGO /INGO facilities.

Similar to previous studies, our quantitative findings indicated that $\operatorname{cost}^{19}$, warm and hospitality service ${ }^{19}$, and confidentiality ${ }^{19-21}$ 
were associated with decision to choose treatment facilities. In contrary to the previous studies, which found that many HIV patients used multiple health care sources including traditional healers ${ }^{22}$, none of the patients in our study reported using traditional medicine or drugstore as their current treatment sources. This probably due to the fact that most of our sample received ART for more than 5 years so they were well informed about benefit of ART and that the use of traditional medicine decline significantly once ART was received ${ }^{6}$.

Duration of diagnosis and place of diagnosis were determinants for first treatment facility. As expected, most patients who practiced self-treatment as the first treatment modality was those who were infected for more than 10 years, when there was limited number of formal treatment facilities. In addition, patients were more likely to receive their treatment at the place where they were diagnosed. In our study, the most common place of diagnosis was INGO/NGO clinics. This could be explained by the process of HIV testing, in which counselling and enrollment of patients to HIV care was provided for people who test HIV positive ${ }^{23}$.

In addition, our study found that key population were more likely to get diagnostic and treatment at INGO/NGO clinic. According to $\mathrm{WHO}^{24}$, key populations include men who have sex with men (MSM), transgender people, people who inject drugs (PWID), and sex workers (SW). These key populations are disproportionately affected by HIV ${ }^{25}$. However, access to HIV testing and treatment of these key populations was limited. One strategy to increase HIV testing was to bring people from key populations to become peer educators, who then motivated their key population peer from their communities to get diagnosed at NGO-run testing and treatment services $^{26}$. This could help explain why key populations were more likely to receive diagnosis and treatment at INGO/NGO clinics. Consistently, we also found that most of the PLHIVs who received their first treatment at INGO/NGO clinics mentioned friends as important person, who motivated them to get treatment.

We found that preference of current treatment facility was associated with first treatment facility. Generally, PLHIV were more likely to continue their treatment at their first treatment facility. The reasons that majority of participants were currently receiving care at INGO/NGO were probably because they received first treatment at INGO/NGO and that they appreciated warm and hospitality services at NGO/INGO. Our study found that comfort and warm services was main reason for choosing treatment facility and that such experiences was perceived at NGO/INGO.

It should be noted that our findings were consistent with the Andersen's behavioural model for health service utilization, which has been used widely to understand health service utilization ${ }^{27}$. According to, the model, health service utilization was affected by three important factors, which are predisposing factors, enabling factors, and need. Examples of predisposing factors are demographic characteristics, attitude, and knowledge. On the other hand, enabling factors include both financing and organizational factors. Examples of financing factors are price, cost-sharing requirement, and insurance status. On the other hand, organization factors include location of health care facilities, health policy, and amount, variety, and distribution of health services and health personnel. They also include family support, travel time to and waiting time at health facility. In our study, we found that predisposing factors (i.e. age, education, key population status), as well as enabling factors (i.e. quality of services and cost) were associated with preferences for health care facility.

Similar to many settings ${ }^{28-31}$, stigma and discrimination by health care providers is common in our study. Nevertheless, it should be noted that most of our participants were key populations that were diagnosed for more than 6 years, the findings might reflect the characterristics of the patients as well as past experiences. Nevertheless, stigma and discrimination may contribute to the delay in treatment as observed in the previous study which found that most of PLHIV in Yangon were late presented in their disease course ${ }^{16}$. Effectively anti-stigma strategies and programs are clearly need to reach the milestone of NSPIII ${ }^{32}$, which aims to reduce discrimination and stigmatization especially in health care for PLHIV.

At present, our study indicated that limited services especially viral load testing and long waiting time were experienced by many patients. As the government plan to increase the role of public facilities to offer ART for PLHIV, effort should be made to ensure that there will be adequate human resource and that viral load testing were offered to the patients in the public ART as one stop service. Also, other supportive care including food and transportation allowance 
should be prepared and offered for PLHIV in needed. It should be noted that our participants were selected from SHGs based on convenient sampling technique, which represented PLHIVs who worked mainly with the NGO/NGO and also remain received treatment. As the result, our findings might represent opinions of the PLHIVs who were satisfied with health care services, especially those provided by NGO/INGO. In addition, most of our participants were key population with the mean duration of HIV diagnosis of 8.6 years. Given these limitations, generalizability of our study findings to other groups of patients should be made with caution.

\section{CONCLUSIONS}

This study revealed that formal care at NGO clinics, followed by the public facilities were the main sources of diagnosis and treatment in PLHIV engaging with SHGs in Yangon. Age, key population status, education, place at diagnosis, and person who motivated to receiving treatment determined the choice of facility for first treatment. First treatment facility was the determinant of current treatment facility. Comfort and warm services was main reason for choosing treatment facility. Stigma and discrimination from health care providers were experienced. Nevertheless, many participants expressed the appreciation of social support and peer support group. To reach the milestone to end HIV epidemic by 2030, effective stigma reduction in health facilities are clearly needed to improve appropriate HIV seeking behavior. In addition, social support should also be provided at the treatment facilities.

\section{ACKNOWLEDGEMENT}

We would like to give our special thanks to Myanmar Positive Group, a National PLHIV Network in Myanmar, and powerful cooperation of Self-Help Groups; 1) Nway Htay Eain, 2) Positive Muslim Group, 3) Golden Future, 4) Arr Mann Thit.

\section{Conflict of interest}

The Author(s) declare(s) that they have no conflicts of interest to disclose.

\section{Funding}

None to declare.

\section{Ethics approval}

Ethical approval for the study was granted by Ethical Review Committee, Department of Medical
Research, Ministry of Health and Sports, the Republic of Myanmar. Ethics/DMR/2018/042

Article info:

Received April 18, 2020

Received in revised form July 20, 2020

Accepted July 27, 2020

\section{REFERENCES}

1. MacKian S, Bedri N, Lovel H. Up the garden path and over the edge: where might health-seeking behaviour take us? Health Policy Plan. 2004;19(3):137-46.

2. Audet CM, Sidat M, Blevins M, Moon TD, Vergara A, Vermund SH. HIV knowledge and health-seeking behavior in Zambézia Province, Mozambique. SAHARA J. 2012;9:141-6.

3. Mills E, Cooper C, Seely D, Kanfer I. African herbal medicines in the treatment of HIV:Hypoxis and Sutherlandia. An overview of evidence and pharmacology. Nutr J. 2005;4(19).

4. Naidoo P. Other health-seeking behaviour of HIV and AIDS patients visiting private sector doctors in the eThekwini Metropolitan Municipality of KwaZuluNatal. S Afr Fam Pract. 2014;56(4):223-28.

5. Peltzer K, du Preez NF, Ramlagan S. Use of traditional, complementary and alternative medicine for HIV patients in KwaZulu Natal, South Africa. BMC Public Health. 2008;8:255-68.

6. Peltzer K, Preez NF, Ramlagan S, Fomundam H, Anderson $\mathrm{J}$, Chanetsa L. Antiretrovirals and the use of traditional, complementary and alternative medicine by HIV patients in Kwazulu-Natal, South Africa: a longitudinal study. Afr J Tradit Complement Altern Med. 2011;8:337-45.

7. Plummer ML, Mshana G, Wamoyi J, Shigongo ZS, Hayes RJ, Ross DA, et al. The man who believed he had AIDS was cured: AIDS and sexual-transmitted infection treatment-seeking behaviour in rural Mwaza. Tanzania. AIDS Care. 2006;18(5):460-6.

8. Mgori NK, Mash R. HIV and/or AIDS-related deaths and modifiable risk factors: A descriptive study of medical admissions at Oshakati Intermediate Hospital in Northern Namibia. Afr J Prim Health Care Fam Med. 2015;7(1):883.

9. Grinsztejn B, Hosseinipour MC, Ribaudo HJ, Swindells S, Eron J, Chen YQ, et al. Effects of early versus delayed initiation of antiretroviral treatment on clinical outcomes of HIV-1 infection: results from the phase 3 HPTN 052 randomised controlled trial. Lancet Infect Dis. 2014;14(4):281-90.

10. Teixeira da Silva DS, Luz PM, Lake JE, Cardoso SW, Ribeiro S, Moreira RI, et al. Poor retention in early care increases risk of mortality in a Brazilian HIV-infected clinical cohort. AIDS Care. 2017;29(2):263-67.

11. UNAIDS. UNAIDS: Country factsheets, Myanmar 2017 [Available from: http://www.unaids.org/en/regionscountries/ countries/myanmar accessed October 2018.

12. UNAIDS2016-2021 Strategy. On the fast-track to end AIDS [Available from: http://www.unaids.org/sites/ default/files/media_asset/20151027_UNAIDS_PCB37 _15_18_EN_rev1.pdf. accessed 15 February 2019.

13. National AIDS Programme. Progress Report 2015, 2015:146.

14. Htet KM, Soe KT, Oo MM, Hone S, Majumdar SS, Oo HN. Early success with retention in care among people living with HIV at decentralized ART satellite sites in 
Yangon, Myanmar, 2015-2016. Front Public Health. 2019;7:124.

15. Linn KZ, Shewade HD, Htet KKK, Maung TM, Hone $\mathrm{S}$, Oo HN. Time to anti-retroviral therapy among people living with HIV enrolled into care in Myanmar: how prepared are we for "test and treat"? Glob Health Action. 2018;11(1):1520473.

16. Aung NM, Hanson J, Kyi TT, Htet ZW, Cooper DA, Boyd MA, et al. HIV care in Yangon, Myanmar; successes, challenges and implications for policy. AIDS Res Ther. 2017;14(1):10.

17. Aung HNY, Riewpaiboon A, Sunantiwat M, Thavorncharoensap M, Praditsitthikorn N. Health Seeking Behaviour and Economic Burden among People Living with HIV in a Commercial City, Myanmar [Master's thesis]. Mahidol Univerisity, 2018.

18. Anderson JG, Bartkus DE. Choice of medical care: a behavioral model of health and illness behavior. J HealthSoc Behav. 1973;14(4):348-62.

19. Ngo AD, Ratliff EA, McCurdy SA, Ross MW, Markham C, Pham HT. Health-seeking behaviour for sexually transmitted infections and HIV testing among female sex workers in Vietnam. AIDS care. 2007;19(7):878-87.

20. Wong WC, Yilin W. A qualitative study on HIV risk behaviors and medical needs of sex workers in a China/Myanmar border town. AIDS patient care STDs. 2003;17(8):417-22.

21. Balasundaram A, Sarkar S, Hamide A, Lakshminarayanan S. Socioepidemiologic profile and treatment-seeking behaviour of HIV/AIDS patients in a tertiary-care hospital in south India. J Health Popul Nutr. 2014;32(4):587-94.

22. Awusabo-Asare K, Anarfi JK. Health-seeking behaviour of persons with HIV/AIDS in Ghana. Health Transit Rev. 1997;7 Suppl:243-56.
23. World Health Organization. Consolidated guidelines on HIV testing services Geneva: World Health Organization, 2015.

24. World Health Organization. Definition of key terms Consolidated ARV guidelines, June 20132013 [Available from: https://www.who.int/hiv/pub/guidelines/arv2013/intro/keyterms/en/.

25. UNAIDS. UNAIDS DATA2019. [ Available from: https://www.unaids.org/sites/default/files/media_asset/ 2019-UNAIDS-data_en.pdf. accessed 15 February 2019.

26. AVERT. HIV and AIDS in Myanmar 2019 [Available from: https://www.avert.org/professionals/hiv-aroundworld/asia-pacific/myanmar accessed 25 March 2020.

27. Babitsch B, Gohl D, von Lengerke T. Re-revisiting Andersen's Behavioral Model of Health Services Use: a systematic review of studies from 1998-2011. Psychosoc Med. 2012;9.

28. Arrey AE, Bilsen J, Lacor P, Deschepper R. Perceptions of Stigma and Discrimination in Health Care Settings Towards Sub-Saharan African Migrant Women Living with Hiv/Aids in Belgium: A Qualitative Study. J Biosoc Sci. 2017;49(5):578-96.

29. Mahendra VS, Gilborn L, Bharat S, Mudoi R, Gupta I, George B, et al. Understanding and measuring AIDSrelated stigma in health care settings: a developing country perspective. SAHARA J. 2007;4(2):616-25.

30. Feyissa GT, Abebe L, Girma E, Woldie M. Stigma and discrimination against people living with HIV by healthcare providers, Southwest Ethiopia. BMC Public Health. 2012;12:522.

31. Dong X, Yang J, Peng L, Pang M, Zhang J, Zhang Z, et al. HIV-related stigma and discrimination amongst healthcare providers in Guangzhou, China. BMC Public Health. 2018;18(1):738.

32. Ministry of Health and Sports. National Strategic Plan on HIV and AIDS Myanmar 2016-2020. 2017; 1-130. 